\title{
Effect of the Ion-Protein Dispersion Interactions on the Protein-Surface and Protein-Protein Interactions
}

\author{
Livia A. Moreira, ${ }^{a}$ Mathias Boström, ${ }^{b}$ Barry W. Ninham, ${ }^{c}$ Evaristo C. Biscaia ${ }^{d}$ and \\ Frederico W. Tavares ${ }^{*}, a$
}

${ }^{a}$ Escola de Química, Universidade Federal do Rio de Janeiro, Cidade Universitária, 21949-900 Rio de Janeiro-RJ, Brazil

${ }^{b}$ Department of Physics and Measurement Technology, Linköping University, SE-581 83 Linköping, Sweden

\author{
${ }^{c}$ Research School of Physical Sciences and Engineering, Australian National University, Canberra, \\ Australia, 0200 \\ ${ }^{d}$ Programa de Engenharia Química, COPPE, Universidade Federal do Rio de Janeiro, \\ 21945-970, Rio de Janeiro-RJ, Brazil
}

\begin{abstract}
A equação de Poisson-Boltzmann é utilizada para calcular o potencial de campo médio característico das interações entre proteínas. Definimos um parâmetro que permite sua comparação com o segundo coeficiente osmótico do virial obtido de diferentes técnicas analíticas experimentais e fornece informação sobre as interações proteína-proteína ou proteína-superfície. Este parâmetro pode ser relacionado à solubilidade de proteínas ou, ainda, ser utilizado na determinação de condições favoráveis para adsorção de proteínas em superfícies ou agregados protéicos. Os cálculos mostram um acordo razoável com os segundos coeficientes do virial experimentais e revelam que é possível predizer diferentes efeitos de Hofmeister observados experimentalmente para soluções protéicas. Demonstramos que a inclusão dos potenciais de dispersão íon-proteína originários das polarizabilidades dos íons e das proteínas pode explicar as séries de Hofmeister. Em particular, damos a evidência para a inversão da série de Hofmeister em função do $\mathrm{pH}$ do meio e do ponto Isoelétrico (pI) da proteína em análise.
\end{abstract}

Interactions between proteins are studied by calculating the potential of mean force based on the Poisson-Boltzmann equation. We define a parameter that allows a comparison between the osmotic second virial coefficients obtained from different experimental analytical techniques and provides information about both protein-protein or protein-surface interactions. It can be related to the protein solubility and be used to determine favorable conditions for protein adsorption on a specific surface or protein aggregation. The calculations show reasonable agreement with the experimental second virial coefficient. They also reveal that it is possible to predict different Hofmeister effects observed experimentally in protein solutions. We demonstrate that the effect of including many-body ion-protein dispersion potentials originating from polarizabilities of ions and proteins may offer an explanation for the Hofmeister series. In particular, we give evidence for the inversion of Hofmeister series as function of $\mathrm{pH}$ for a given protein.

Keywords: van der Waals interactions, Hofmeister series, protein adsorption, osmotic second virial coefficient

\section{Introduction}

Protein adsorption and protein precipitation are involved in a wide range of phenomena and applications.

*e-mail: tavares@eq.ufrj.br
The deposition of blood proteins on to medical devices and the subsequent modification of their biological responses, the bacterial fouling of ship hulls and the blockage of filtration membranes in bio-separation processes are examples of unfavorable aspects of protein adsorption. The extensive uses of a variety of proteins in 
food emulsion stabilization and in the fabrication of biosensors are examples of useful applications.

Protein adsorption from biofluids on to solids plays a mediating role in bioaccumulation, systemic foreign body reactions, tissue regeneration, and is, therefore, crucial for biocompatibility and performance of medical devices. In line with colloid theories correlations exist between the accumulation of biomass and the surface charge on a solid surface. Given the specific needs of cardiovascular implants, tissue engineering templates and diagnostic microdevices, there is a new focus on an emerging paradigm for the design of new materials. Biosurface engineering utilizes the adjustment of molecular level surface structure to obtain bioactive materials. Desired functions of biointerfaces are mainly based on principles of molecular recognition. In order to understand protein adsorption patterns the surface properties of the substrate, the nature of the protein and the solution conditions have to be considered.

The understanding of how the solution $\mathrm{pH}$, salt concentration, and salt type influence the protein-surface and protein-protein interactions is useful information for the design and optimization of protein separation and purification processes such as salt-induced protein precipitation, protein crystallization, and affinity chromatography. ${ }^{1-3}$ Furthermore, attractive protein-protein interactions may result in protein precipitation, aggregation, or fibril formation, as observed e.g., in Alzheimer's, ${ }^{4}$ Parkinson's, ${ }^{5}$ and Huntington's ${ }^{6}$ diseases. Knowledge of the interactions between protein molecules in solution is then fundamental for describing protein behavior in nature and in bioprocesses.

George and Wilson ${ }^{7}$ demonstrated the importance of the specificity of protein-protein interactions in protein crystallization in 1994. They proposed that the success of crystallization is correlated with the magnitude of the second virial coefficient. They found a range for this coefficient over which crystallization is favored. Outside this "window", crystallization may not occur. For large positive second virial coefficients, crystallization does not occur at all by any nucleation process and, for large negative values, protein aggregation rather than crystallization takes place.

Ten Wolde and Frenkel ${ }^{8}$ have shown that this crystallization window corresponds to a metastable liquid-liquid critical point in the vicinity of the liquid-solid equilibrium. Close to this critical point, the free energy barrier for crystallization is strongly reduced and the crystal nucleation rate increases by many orders of magnitude.

Information about protein interactions are often characterized in terms of the osmotic second virial coefficient. This is because it can be measured using traditional colloidal characterization techniques like static and dynamic light scattering, ${ }^{7,9,10}$ membrane osmometry, ${ }^{11,12}$ sedimentation, ${ }^{13}$ and chromatographic methods. ${ }^{14-16}$ However, these techniques have some limitations. They are generally labor-intensive and expensive in terms of time and protein cost. Estimating the second virial coefficient would be a useful tool but it is necessary first to determine the potential of mean force between two colloidal particles. Here, we study protein interactions through a simple model based on an extension of the non-linear Poisson-Boltzmann equation.

The goal of this work is to estimate a parameter that provides information about the adsorption and second virial coefficients of proteins in solution at different $\mathrm{pH}$ and salt concentrations. We explore protein interactions via a simple model that calculates the interactions between a protein in solution and a surface. The surface is considered as a homogeneous molecularly smooth charged wall with a characteristic dielectric constant. The mobile protein is treated as a macroion in solution characterized by its radius and charge, as shown in Figure 1. The ions and macroion distribution are calculated using the nonlinear Poisson-Boltzmann equation. In the case of second virial coefficient, the surface is treated as an immobile protein, with a charge-density and dielectric constant.

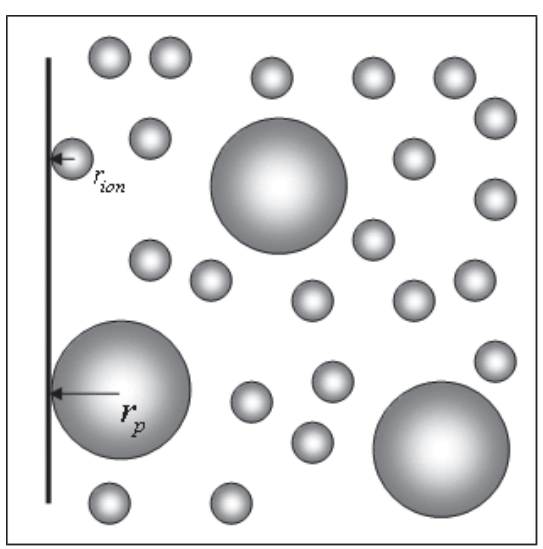

Figure 1. Scheme of the simple model proposed to estimate the second virial coefficient. Proteins and ions in solution interact with the charged surface through electrostatic and van der Waals interactions and they are distributed near the surface according to the Poisson-Boltzmann equation.

Even though the model is a vastly simplified view of this complex system, using the Poisson-Boltzmann equation, we intend to demonstrate that the inclusion of the ion-surface and macroion-surface van der Waals dispersion interactions via an extension of the PoissonBoltzmann equation may offer an explanation for a number of unexplained experimental observations. 
Hofmeister showed during the 1880 s in a series of experiments ${ }^{17}$ that protein precipitation depends on salt type. The Hofmeister series ranks the salts according to their effectiveness to precipitate not just for protein substances but also for any other colloidal system. We investigate here the relative effectiveness of various ions on the interaction of proteins and give evidence that the effectiveness may follow a direct or a reverse Hofmeister sequences according to the relative values of $\mathrm{pH}$ of the solution and the isoeletric point (pI) of a specific protein.

\section{The potential of mean force from the Poisson-Boltzmann equation}

The potential of mean force was first evaluated via the linearized version of the Poisson-Boltzmann equation in the classic papers of Gouy ${ }^{18}$ and Chapman. ${ }^{19}$ In this theory, it is assumed that the ions are point charges embedded in a continuum of constant dielectric. These are distributed according to Boltzmann statistics and interact with all the other charges via a mean field obeying the Poisson equation. The classical theory accounts only for electrostatics and thermal motion and neglects several important effects such as dispersion forces, ion fluctuation, hydration, ion size effects, and the water structure at interfaces. Several extensions of the theory aim to include one or more of these contributions in the model within the framework of mean-field Poisson-Boltzmann theory.

The Poisson-Boltzmann approach has the advantage of simplicity and is surprisingly accurate, at least for univalent and small ions in a range of low electrolyte concentrations (usually less than about $0.05 \mathrm{~mol} \mathrm{~L}^{-1}$ ).

In this model the ions are considered as point charges that obey the Boltzmann distribution. But the interaction between an ion and a surface is not only due to an electrostatic potential $\phi$. Each ion experiences a further additive term that come from dispersion interactions, $U_{i}$. These interactions depend on the polarizabilities and dielectric susceptibilities (as a function of frequency) of ions and macroions. Then, the modified Boltzmann distribution of ions (or macroions) in the solution are given by, ${ }^{20-26}$

$c_{i}(x)=c_{0 i} \exp \left(-\frac{\left[v_{i} e \phi(x)+U_{i}(x)\right]}{k_{B} T}\right)$

where the index $i$ holds for ion (or macroion) species, $x$ is the distance from the center of ion (or macroion) to the charged surface, $c_{i}$ stands for the ion concentration, $c_{o i}$ is the ion concentration at the bulk reservoir, $v_{i}$ is the ion valence, $e$ is the elementary charge, $k_{B}$ is the Boltzmann constant, and $T$ is the absolute temperature.

The ion-surface (or protein-surface) dispersion interaction $U_{i}$ within the pair summation approximation (the Hamaker approach) can be approximated as,

$U_{i}(x)=\left\{\begin{array}{l}\infty \text { for } x<r_{i} \\ -\frac{H_{i} r_{i}^{3}}{x^{3}} \text { for } x \geq r_{i}\end{array}\right.$

where $r_{i}$ is the radius of particle $i$ (cations, anions or macroions). The dispersion coefficient $\left(H_{i}\right)$ will be different for different combinations of particle and surface. By dispersion forces we mean the totality of electrodynamic fluctuation forces that are included and accessible via Lifshitz theory. ${ }^{27}$ These include e.g. many-body permanent dipole-dipole; dipole-induced dipole; and induced dipole-induced dipole forces. In dilute media these are respectively the familiar Keesom, Debye, and London van der Waals dispersion forces, respectively.

We have used the dispersion coefficient in aqueous solution presented in Table 1 for ion-surface and $H=6 k_{B} T$ for macroion-surface interactions. The same potential is used to account for the dispersion interaction between a mobile protein of radius $r_{p}$ and a protein on a surface (immobile protein).

Table 1. Dispersion coefficents for iron-surface at $298 \mathrm{~K}^{28}$

\begin{tabular}{lccc}
\hline Anions & $H / 8 k_{B} T$ & Cations & $H / 8 k_{B} T$ \\
\hline $\mathrm{F}^{-}$ & 0.435 & $\mathrm{Na}^{+}$ & 0.138 \\
$\mathrm{Cl}^{-}$ & 1.086 & $\mathrm{~K}^{+}$ & 0.574 \\
$\mathrm{Br}^{-}$ & 1.348 & $\mathrm{Ca}^{2+}$ & 0.385 \\
$\mathrm{I}^{-}$ & 1.735 & $\mathrm{Ba}^{2+}$ & 1.021 \\
\hline
\end{tabular}

The combination of the Boltzmann distribution and the Poisson equation for net charge density leads to a nonlinear second-order differential equation. Therefore, the Poison-Boltzmann equation is written, in Cartesian coordinates as,

$\frac{d^{2} \phi(x)}{d x^{2}}=-\frac{4 \pi e}{\varepsilon_{o} \varepsilon_{w}} \sum_{i} v_{i} c_{o i} \exp \left(-\frac{\left[v_{\mathrm{i}} e \phi(x)+U i(x)\right]}{k_{B} T}\right)$

where, $\varepsilon_{0}=8.854 \times 10^{-12} \mathrm{C}^{2} \mathrm{~J}^{-1} \mathrm{~m}^{-1}$ is the electric constant, $\varepsilon_{w}$ is the dielectric constant of the solvent, $\phi$ is the selfconsistent electrostatic potential experienced by the ions, and the potential energy $U_{i}$ are the dispersion interactions experienced by cations, anions and macroions (proteins) near the planar surface. 
The boundary conditions follow from global charge neutrality. The first boundary condition is that the electric field vanishes at infinity $\left(x=\infty \rightarrow \phi=0\right.$ and $\left.U_{i}=0\right)$. The second boundary condition is originated once the charge on the surface generates an electric field. Since the field always points radially away from the charge (or gaussian surface), according to Gauss' law we write it as,

$\left.\frac{d \phi}{d x}\right|_{x=r_{\text {ion }}}=-\frac{e v_{p} \theta}{\pi r_{p}^{2} \varepsilon_{o} \varepsilon_{w}}$

where $r_{p}$ and $v_{p}$ are, respectively, the radius and valence of the protein and $\theta$ is the fraction of covered area. The covered area gives the number of proteins fixed on the surface. We assume that immobile proteins are completely spread on the surface, and the charge density depends on the amount of protein per area (covered area). We have made the assumption that the ions cannot get any closer to the effective protein surface than one ion radius $\left(r_{i o n}\right)$, consistent with equation 2 , and the mobile-phase protein cannot get any closer to the effective surface than one protein radius (Figure 1).

In this work, we calculate the osmotic second virial coefficients $^{29}$ from:

$B_{22}=\frac{N_{A}}{2 M^{2}} \int_{0}^{\infty}\left[1-e^{-W(x) / k_{B} T}\right] 4 \pi x^{2} d x$

where $N_{A}$ is Avogadro's number, $M$ is the molecular weight of the protein, and $x$ is the center-to-surface separation.

The potential of mean force, $W(x)$, is defined such that its negative derivative with respect to the distance is the force between two solutes, averaged over all configurations of the solvent molecules. ${ }^{30}$ Here, the potential of mean force is between a globular protein and a planar surface (immobile protein), and the potential of mean force depends on the hard sphere, electrostatic, and van der Waals interactions. The main electrostatic force between two similar proteins is the Coulombic repulsion, which depends upon charge and ionic strength. Note that the effective electrostatic forces also depend on the nature and magnitude of the dispersion forces acting betweens ions and the surface. The electrostatic and dispersion potentials form what is usually called the DLVO potential model, which were described by Derjaguin-Landau-Verwey-Overbeek in their theory. ${ }^{31}$

In the calculation of the osmotic second virial coefficient, the potential considered here is:

$W(x)=\left\{\begin{array}{l}\infty \text { for } x<r_{p} \\ \operatorname{ve} \phi(x)-\frac{H_{p} r_{p}^{3}}{x^{3}} \text { for } x \geq r_{p}\end{array}\right.$ where $\phi$ is the electrical potential from the PoissonBoltzmann equation and $H_{p}$ is the van der Waals coefficient between two proteins (one in solution, mobile-protein, and another on surface, immobileprotein). It is important to notice that in this model, in contrast to original DLVO model, the electrical field obtained by Poisson-Boltzmann equation depends direct and indirectly on various factors including the van der Waals interactions between ions and immobile protein and between mobile and immobile proteins. In the classical DLVO theory the electrostatic forces are treated separately in a non-linear theory. The dispersion forces are treated separately via the linear Lifshitz theory. This can be shown to be thermodynamically inconsistent and this theory does not include specific ion effects. The present approach does. ${ }^{23}$

\section{Results and Discussion}

\section{Parameters}

We are interested in evaluating the trends in the second virial coefficient pattern for lysozyme interactions at a variety of solution conditions. We choose lysozyme since it is the protein usually used in studies of protein interactions and one for which there are much experimental data available in the literature.

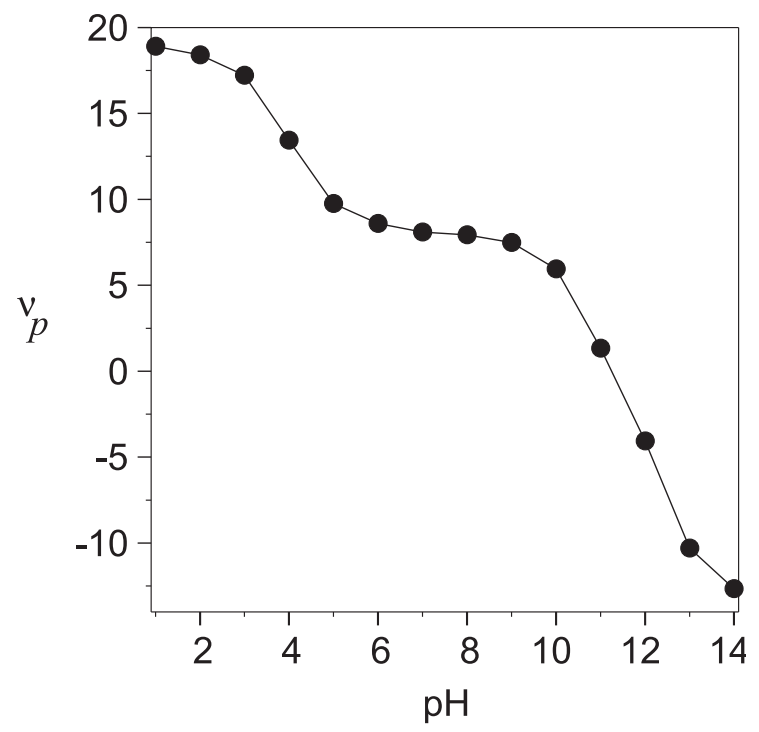

Figure 2. Valence of lysozyme at different $\mathrm{pH}$.

Lysozyme is a globular protein with well-defined molecular dimensions in its native state, and sphericity is a reasonable assumption for its shape. Literature radius and molecular weights for lysozyme are reported ${ }^{15}$ to be $17.2 \AA$ and $14.0 \mathrm{kDa}$, respectively. Its charge depends on the $\mathrm{pH}^{32}$ according to Figure 2 and the dispersion 
coefficient between two lysozymes was proposed in previous studies to be around $6 k_{B} T .^{15,33}$

Each protein is modeled as a uniformly-charged dielectric sphere with radius $r_{p}$ and all ions are considered to have the same radius $\left(r_{i o n}=2 \AA\right)$. Usually, the difference in ion size for similar ions is quite small, and to highlight the effects of the dispersion potentials we take it to be the same for all ions. In this model the lyzosyme concentration in solution, $c_{p}$, and the fraction of covered area, $\theta$, are two parameters that were experimentally determined by Teske et al. ${ }^{15}$ We found through a careful analysis that in the studied parameter range, these parameters $\left(c_{p}\right.$ and $\left.\theta\right)$ have a much weaker influence than the dispersion coefficient on the second virial coefficient. Here, we adopted the lysozyme concentration in solution $c_{p}=0.12 \mathrm{~g} \mathrm{~L}^{-1}$ and the fraction of covered area as $\theta=$ 0.36 (these are values used by Teske et al..$^{15}$ in their experimental study).

To determine the charge density on the surface and use it with the second boundary condition (equation 4), we consider that the planar surface would be partially covered with proteins (Figure 3). The fraction of covered area represents the ratio of the area covered by protein to the total available area. Knowing the area occupied by immobile protein and the radius of protein, we can determine how many proteins are fixed on the surface. The charge density on the surface is determined assuming that the total protein net charge covering the surface is distributed uniformly on the surface.

\section{Lysozyme-lysozyme interactions}

Here, we are interested in evaluating the trends in the second virial coefficient between two proteins, with variation in both electrolyte concentration and $\mathrm{pH}$. Therefore, we have calculated the second virial coefficient for lysozyme interactions at a variety of solution conditions. We calculate $B_{22}$ for lysozyme at $\mathrm{pH} 4.5$ as a function of sodium chloride concentration and as a function of the solution $\mathrm{pH}$ at a fixed sodium chloride concentration $\left(1 \mathrm{~mol} \mathrm{~L}^{-1}\right)$; with temperature fixed at $25^{\circ} \mathrm{C}$.

The addition of electrolyte reduces the range of the electrostatic interactions so the second virial coefficient decreases, i.e., becomes more negative with increasing salt concentration. The behavior at low ionic concentration is governed by the long-range electrostatic interactions (Figure 4). ${ }^{15,34}$ In this set of calculations, proteins have the same net charge, thus the repulsive interaction dominates. But with the increase of salt concentration, proteins are screened by the ions, reducing the net stregth
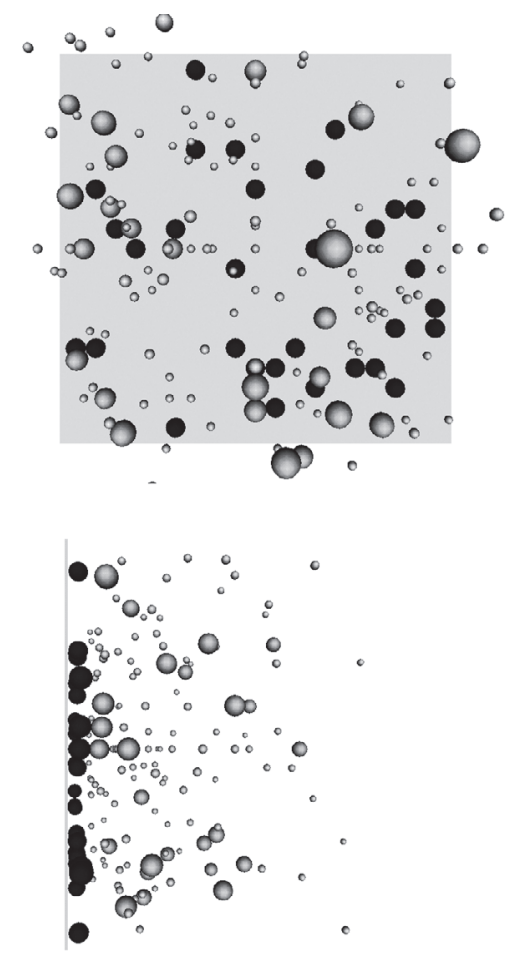

Figure 3. Perpendicular and parallel views of the system, schematically shown, where the dark-particles are the immobile proteins, fixed on the inert support and the gray-particles are the mobile proteins in aqueous solution. The smaller and light-gray spheres represent ions in solution.

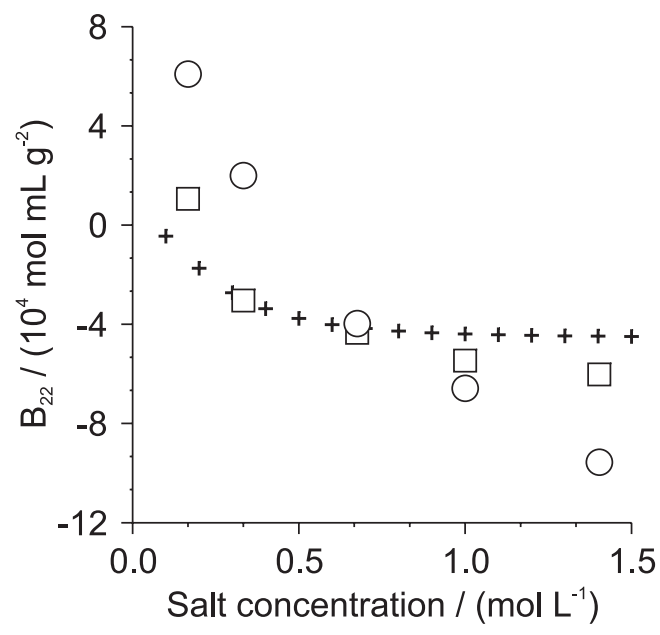

Figure 4. Comparison of the second virial coefficient for lysozyme interactions in $\mathrm{NaCl}$ at $\mathrm{pH} 4.5$. Symbols are for calculated (crosshairs) and for light scattering experiments SLS (open squares), and for chromatograph experiments (open circles).

of the electrostatic forces in such way that the attractive van der Waals forces become evident. This leads to more negative virial coefficients. However an effect of salt concentration is observed until a limit is reached, at which additional increase of salt concentration has no further effect on the second virial coefficient. 
It is seen that the osmotic second virial coefficients obtained by the method presented here follow similar trends compared to those reported in literature. It should be noted that the absolute values may not match because different techniques may result in different second virial coefficients. ${ }^{12,13,15,16}$ These differences could be attributed not only to the simplicity of theory used, but also to the effect of systematic errors associated with the experimental techniques; for example, in the chromatography techniques there is no guarantee that the many-body interaction would not play an important rule. In chromatography beds, a protein in mobile phase can interact with several immobilized proteins; depend on the protein concentrations in bulk and surface phases.

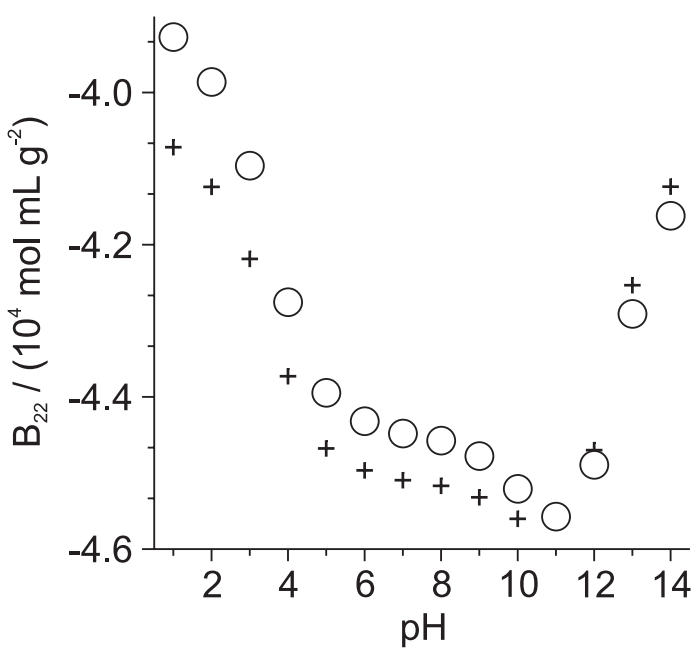

Figure 5. Dependence of the second virial coefficient on the $\mathrm{pH}$ for lysozyme interactions at ionic strength of $1 \mathrm{~mol} \mathrm{~L}^{-1}$. Symbols are for $\mathrm{NaCl}$ (crosshairs) and for non polarizable monovalent ions (open circles).

The interplay of the intermolecular forces can explain the qualitative trend in the second virial coefficient data obtained from changes of $\mathrm{pH}$ of the solutions, as shown in Figure 5. The protein is positively charged at low $\mathrm{pH}(\mathrm{pH}<$ $\mathrm{pI}$ ), therefore, repulsive forces between proteins dominate and the second virial coefficient is positive. ${ }^{35}$ The charge of the protein decreases with increasing pH (Figure 2), increasing the importance of the attractive van der Waals interaction. The approach of the $\mathrm{pH}$ to the isoelectric point reduces the electrostatic repulsive forces leading to the attractive van der Waals forces becoming more evident. The second virial coefficient becomes more negative. For $\mathrm{pH}$ higher than the $\mathrm{pI}$, the proteins are negatively charged and therefore the repulsive forces become very important again.

\section{Ionic specific effects acting on Hofmeister sequences}

In 1888 Hofmeister showed that protein solubility is ion-pair-specific. Ries-Kautt and Ducruix ${ }^{36}$ revealed that the main variation in ion specific Hofmeister effects could be attributed to anions. In their work the solubility followed a so-called reversed Hofmeister series. This was of much interest because the corresponding original paper of Hofmeister used hen-egg white protein and gave exactly the opposite anion sequence. This is termed a direct Hofmeister series. Some time ago, the same group demonstrated a direct order for the same protein studied at $\mathrm{pH}$ higher than $\mathrm{pI} .{ }^{37} \mathrm{In}$ fact the reversal of the Hofmeister series has been long known and its explanation poses a key test of any theory of specific ion effects. ${ }^{26,38,39}$ Inspired by the more recent results, some researchers have investigated the behavior of different proteins at $\mathrm{pH}$ conditions below and above the protein $\mathrm{pI}{ }^{3}$

Boström et al. ${ }^{25}$ have demonstrated, through a study of two parallel plates, that this phenomenon can be understood if the ion-surface dispersion interactions are taken into account. This is because while electrostatic forces often dominate at low salt concentrations, dispersion forces become important at high salt concentrations where the electrostatic forces are weakened due to screening. At these condition, the counterion plays a very important role; for $\mathrm{pH}<\mathrm{pI}$ the anions are the counterions and for $\mathrm{pH}>\mathrm{pI}$ the cations are the counterions.

Here, we are interested in investigating whether the calculated second virial coefficients show up the correct Hofmeister series for $\mathrm{pH}$ below and above the $\mathrm{pI}$. We have performed calculations to study the influence of ionic dispersion potentials of anions and cations on the second virial coefficients. The calculations were for lysozyme at a variety of $\mathrm{pH}$ conditions and different salts at $25^{\circ} \mathrm{C}$.

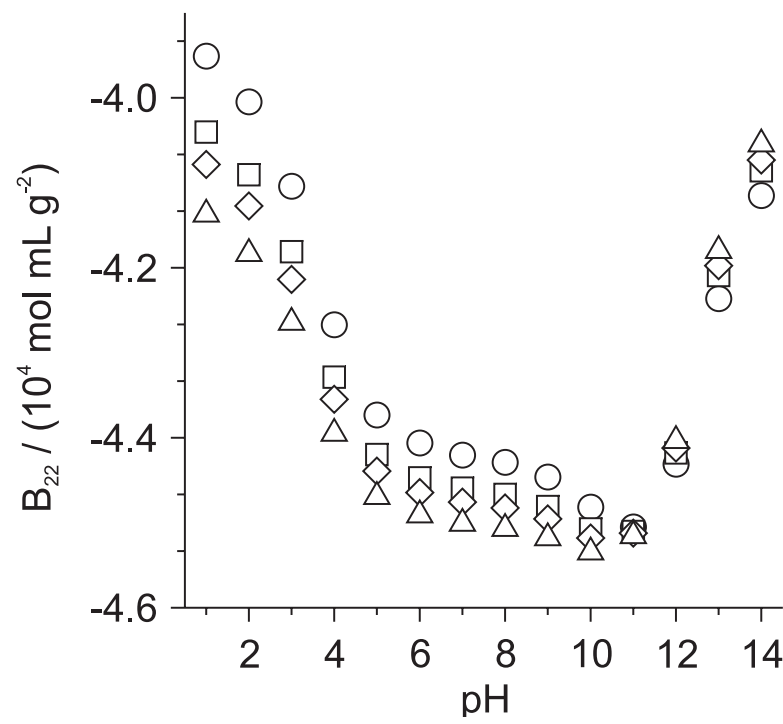

Figure 6. Dependence of the second virial coefficient on the salt type and $\mathrm{pH}$ for lysozyme interactions at ionic strength of $1 \mathrm{~mol} \mathrm{~L}^{-1}$. Symbols are for $\mathrm{NaF}$ (open circles), for $\mathrm{NaCl}$ (open squares), for $\mathrm{NaBr}$ (open diamonds), and for NaI (open triangles). 


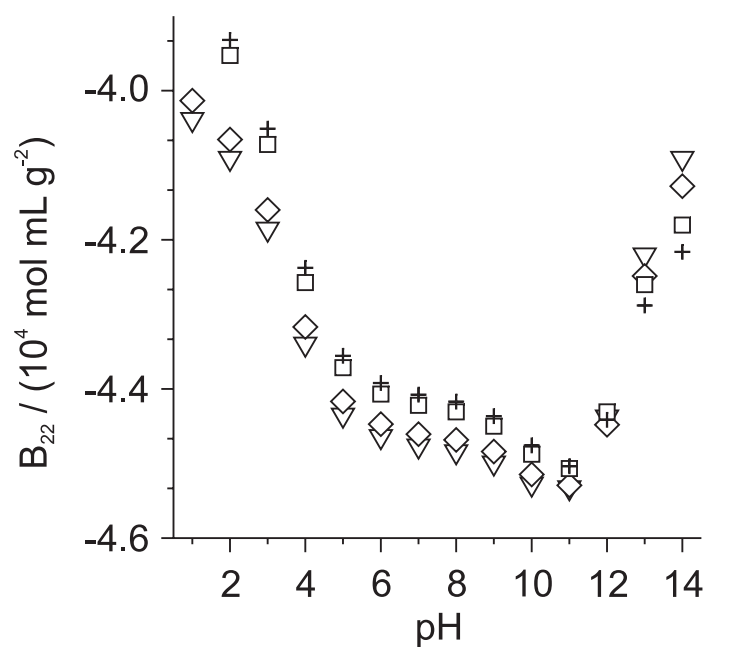

Figure 7. Dependence of the second virial coefficient on the salt type and $\mathrm{pH}$ for lysozyme interactions at ionic strength of $1 \mathrm{~mol} \mathrm{~L}^{-1}$. Symbols are for $\mathrm{NaCl}$ (down triangles), for $\mathrm{KCl}$ (open diamonds), for $\mathrm{CaCl}_{2}$ (open squares), and for $\mathrm{BaCl}_{2}$ (crosshairs).

The calculations illustrated in Figures 6 and 7 demonstrate clearly that the classical DLVO cannot be used to adequately characterize and describe the rich behavior of protein interactions, especially the ion-type effect. The interactions between both proteins (mobile and immobile) as well as between any two surfaces should be augmented by the van der Waals interactions between ion and surface, mainly because the dispersion potential is largely sensitive to electrolyte type, a contribution neglected by the classical DLVO model.

We choose a high ionic strength to investigate the importance of a series of anions (Figure 6) and a series of cations (Figure 7). In Figure 6, the anion specificity effect is investigated theoretically with different sodium salts. Figure 7 shows corresponding results for cation effects, using different chloride salts.

First, consider an example in which the $\mathrm{pH}$ is below the isoelectric point, i.e., for lysozyme, $\mathrm{pH}<11$. Because bromide is more polarizable than chloride and because more polarizable ions adsorb more at protein surfaces, ${ }^{28}$ it is expected that the protein-protein interactions in $\mathrm{NaCl}$ solution are more repulsive than in $\mathrm{NaBr}$ solution. Such behavior was experimentally verified by Taratuta et $a l .^{40}$ and our calculations satisfy such an expectation. It is usually assumed that counterion effects are larger than co-ions effects; however it can be noticed in Figure 7 that there are also some significant co-ion effects at high salt concentration.

In Figure 6, where the anions are counterions for $\mathrm{pH}<\mathrm{pI}$, the repulsive double layers forces increase in a reverse order Hofmeister series $\left(\mathrm{F}^{-}>\mathrm{Cl}^{-}>\mathrm{Br}^{-}>\mathrm{I}^{-}\right)$, while for $\mathrm{pH}>\mathrm{pI}$ where anions are co-ions, the forces increase in direct order $\left(\mathrm{I}^{-}>\mathrm{Br}^{-}>\mathrm{Cl}^{-}>\mathrm{F}^{-}\right)$. In Figure 7, where cations are co-ions for $\mathrm{pH}<\mathrm{pI}$, the repulsive double layers forces increase in a direct order Hofmeister series $\left(\mathrm{Ba}^{2+}>\right.$ $\mathrm{Ca}^{2+}>\mathrm{K}^{+}>\mathrm{Na}^{+}$), while at $\mathrm{pH}>\mathrm{pI}$ where cations are counterions, the forces increase in the reverse order $\left(\mathrm{Na}^{+}>\right.$ $\left.\mathrm{K}^{+}>\mathrm{Ca}^{2+}>\mathrm{Ba}^{2+}\right)$. In other words, for anions or cations, different Hofmeister sequences were observed when the $\mathrm{pH}$ is below or above the isoelectric point. Our results are in qualitative agreement with experimental results.

\section{Conclusions}

We have calculated protein interactions in a variety of solution conditions. Our results for lysozyme interactions show reasonable agreement with the osmotic second virial coefficients from light scattering and chromatographic methods. The non-linear Poisson-Boltzmann equation is used with a simplified model to calculate the potential of mean force, and then the thermodynamics properties of protein solutions. In our calculations we used the theoretically expected Hamaker constants for the ionprotein and protein-protein dispersion interactions, and therefore we emphasize that our results do not have any adjustable parameters.

The effects of including many-body ion-protein dispersion potentials originating from polarizabilities of ions and proteins offer an explanation for several, experimentally observed, Hofmeister series, and how they depend on $\mathrm{pH}$ of the solution and on $\mathrm{pI}$ of the protein. It is important to notice that taking into consideration the dispersion potential, augmented by others potentials like solvation energy, could help to explain the Hoffmeister effects to a variety of others systems, for instance, the surface tension in air-water interface models. ${ }^{26}$

\section{Acknowledgments}

LAM, FWT and ECB thank CAPES, CNPq and FAPERJ, the Brazilian agencies for scholarship and for supporting part of this project. M. B. thanks the Swedish Research Council for financial support.

\section{References}

1. Chiew, Y. C.; Kuehner, D. E.; Blanch, H. W.; Prausnitz, J. M.; AICHE J. 1995, 41, 2150.

2. Piazza, R.; Curr. Opin. Colloid Interface Sci. 2000, 5, 38.

3. Tardieu, A.; Bonnete, F.; Finet, D. S.; Vivares, D.; Acta Crystallogr., Sect. D: Biol. Crystallogr. 2002, 58, 1549.

4. Lomakin, A.; Teplow, D.B.; Kirschneri, D.A.; Benedek, G.B.; Proc. Natl. Acad. Sci. 1997, 94, 7942. 
5. Conway, K.A.; Harper, J. D.; Lansbury Jr., P. T.; Biochemistry 2000, 39, 2552.

6. Heiser, V.; Scherzinger, E.; Boeddrich, A.; Nordhoff, E.; Lurz, R.; Schugardt, N.; Lehrach, H.; Wanker, E. E.; Proc. Natl. Acad. Sci. U. S. A. 2000, 97, 6739.

7. George, A.; Wilson, W. W.; Acta Crystallogr., Sect. D: Biol. Crystallogr. 1994, 50, 361.

8. Ten Wolde, P. R.; Frenkel, D.; Theor. Chem. Acc. 1999, 101, 205.

9. Velev, O. D.; Kaler, E. W.; Lenhoff, A. M.; Biophys. J. 1998, $75,2682$.

10. Muschol, M.; Rosenberger F.; J. Chem. Phys. 1995, 103, 10424.

11. Haynes, C.; Tamura, K.; Körfer, H.; Blanch, H. W.; Prausnitz, J. M.; J. Phys. Chem. 1992, 96, 905.

12. Schaink, H. M.; Smit, J. A. M.; Phys. Chem. Chem. Phys. 2000, 2, 1537.

13. Behlke, J.; Ristau, O.; Biophys. Chem. 1999, 76, 13.

14. Tessier, P. M.; Abraham, M.; Lenhoff, A. M.; Sandler, S. I.; Biophys. J. 2002, 82, 1620.

15. Teske, C. A.; Blanch, H. W.; Prausnitz, J. M.; J. Phys. Chem. B 2004, 108, 7437.

16. Teske, C. A.; Blanch, H. W.; Prausnitz, J. M.; Fluid Phase Equilib. 2004, 219,139.

17. Kunz, W.; Henle, J.; Ninham, B. W.; Curr. Opin. Colloid Interface Sci. 2004, 9, 19.

18. Gouy, G.; J. Phys. Theor. Appl. 1910, 9, 455.

19. Chapman, D.L.; Philos. Mag. 1913, 25, 475.

20. Boström, M.; Williams, D. R. M.; Ninham, B. W.; Langmuir 2002, 18, 6010 .

21. Boström, M.; Williams, D. R. M.; Ninham, B. W.; Langmuir 2002, 18, 8609 .

22. Boström, M.; Craig, V. S. J.; Albion, R.; Williams, D. R. M.; Ninham, B. W.; J. Phys. Chem. B 2003, 107, 2875.

23. Boström, M.; Williams, D. R. M.; Ninham, B. W.; Biophys. J. 2003, 85, 686.
24. Boström, M.; Williams, D. R. M.; Ninham, B. W.; Eur. Phys. J. E 2004, 13, 239.

25. Boström, M.; Tavares, F. W.; Finet, S.; Skouri-Panet, F.; Tardieu, A.; Ninham, B. W.; Biophys. Chem. 2005, 117, 217.

26. Boström, M.; Kunz, W.; Ninham, B. W.; Langmuir 2005, 21, 2619.

27. Ninham, B. W.; Adv. Colloid Interface Sci. 1999, 83, 1-17.

28. Tavares, F. W.; Bratko, D.; Blanch, H. W.; Prausnitz, J. M.; J. Phys. Chem. B 2004, 108, 9228.

29. Moon, Y. U.; Anderson, C. O.; Blanch, H. W.; Prausnitz, J. M.; Fluid Phase Equilib. 2000, 168, 229.

30. McMillan Jr., W. G.; Mayer, J. E.; J. Chem. Phys. 1945, 13, 276.

31. Verwey, E. J. W.; Overbeek, J. T. K.; Theory of Stability of Lyophobic Colloids; Elsevier: New York, 1948.

32. Grant, M. L.; J. Phys. Chem. B 2001, 106, 2858.

33. Prausnitz, J. M. Pure Appl. Chem. 2003, 75, 859.

34. Curtis, R. A.; Ulrich, A. M.; Prausnitz, J. M.; Blanch, H. W.; Biotechnol. Bioeng. 2002, 79, 367.

35. Retailleau, P.; Ries-Kautt, M.; Ducruix, A.; Biophys. J. 1997, 73, 2156

36. Ries-Kautt, M.; Ducruix, A.; J. Biol. Chem. 1989, 264, 745.

37. Carbonnaux, C.; Ries-Kautt, M.; Ducruix, A.; Protein Sci. 1995, 4, 2123.

38. Loeb, J.; Science 1920, 52, 449.

39. Gustavson, K. H.; In Colloid Symposium Monograph; Weiser, H.B., ed.; The Chemical Catalog Company Inc.: New York, 1926 and references therein.

40. Taratuta, V. G.; Holschbach, A.; Thurston, G. M.; Blankschtein D.; Benedek, G. B.; J. Phys. Chem. 1990, 94, 2140.

Received: March 22, 2006

Web Release Date: January 26, 2007 